\title{
The Moderating Role of Self-Control and Financial Strain in the Relation between Exposure to the Food Environment and Obesity: The GLOBE Study
}

\author{
Joreintje D. Mackenbach $1, *(0)$, Marielle A. Beenackers ${ }^{2}$, J. Mark Noordzij ${ }^{2}$, \\ Joost Oude Groeniger ${ }^{2,3}$, Jeroen Lakerveld ${ }^{1,4,5}$ and Frank J. van Lenthe ${ }^{2,5}$ \\ 1 Department of Epidemiology and Biostatistics, VU University Medical Center, Amsterdam Public Health \\ Research Institute, 1007 MB Amsterdam, The Netherlands; je.lakerveld@vumc.nl \\ 2 Department of Public Health, Erasmus University Medical Center, 3000 CA Rotterdam, The Netherlands; \\ m.beenackers@erasmusmc.nl (M.A.B.); j.m.noordzij@erasmusmc.nl (J.M.N.); \\ j.oudegroeniger@erasmusmc.nl (J.O.G.); f.vanlenthe@erasmusmc.nl (F.J.v.L.) \\ 3 Department of Public Administration and Sociology, Erasmus University, \\ 3000 DR Rotterdam, The Netherlands \\ 4 Julius Center for Health Sciences and Primary Care, University Medical Center Utrecht, \\ 3584 CX Utrecht, The Netherlands \\ 5 Faculty of Geosciences, Department of Human Geography and Spatial Planning, Utrecht University, \\ 3508 TC Utrecht, The Netherlands \\ * Correspondence: j.mackenbach@vumc.nl; Tel.: +31-20-444-8198
}

Received: 11 January 2019; Accepted: 21 February 2019; Published: 25 February 2019

\begin{abstract}
Low self-control and financial strain may limit individuals' capacity to resist temptations in the local food environment. We investigated the moderating role of self-control and financial strain in the relation between the food environment and higher body weight. We used data from 2812 Dutch adults who participated in the population-based GLOBE study in 2014. Participants' home addresses and the location of food retailers in 2013 were mapped using GIS. The density of fast food retailers and the totality of food retailers in Euclidean buffers of 250, 400 and $800 \mathrm{~m}$ around the home were linked to body mass index and overweight status. A higher density of fast food outlets (B $(95 \%$ confidence interval $(\mathrm{CI}))=-0.04(-0.07 ;-0.01))$ and the totality of food outlets $(\mathrm{B}(95 \% \mathrm{CI})=-0.01(-0.01 ;-0.00))$ were associated with a lower body mass index. Stratification showed that associations were strongest for those experiencing low self-control or great financial strain. For example, every additional fast food outlet was associated with a 0.17 point lower BMI in those with great financial strain, while not significantly associated with BMI in those with no financial strain. In conclusion, we did find support for a moderating role of self-control and financial strain, but associations between the food environment and weight status were not in the expected direction.
\end{abstract}

Keywords: body weight; cognitive bandwidth; food environment; GIS; interaction

\section{Introduction}

Local food environments are part of the complex web of factors that influence food choices and obesity [1-6]. Ubiquitous access to convenient and inexpensive food has changed normative eating behaviour, with more people snacking and eating out-of-home [7]. Living in an 'obesogenic environment' with high accessibility to energy-dense and ultra-processed foods and repeated exposure to food cues such as advertisements, smells and promotions increases the likelihood that individuals indulge themselves [8]. These temptations-i.e., the omnipresence of tempting food cues — distract from long-term health objectives including healthy diet and body weight. 
Tempting cues are considered especially influential in people with a burdened mental capacity, whose ability to regulate the impact of temptations on behaviour is limited $[9,10]$. Self-control refers to the capacity to override and replace a dominant response (e.g., give in to a tempting food cue) with a response more in line with longer term goals (e.g., sticking to a dietary plan) [11-13]. Self-control is facilitated by self-regulation. Although a topic of debate [14], self-regulation is hypothesized to be functionally confined [15]; that is, individuals that used self-control on one task will function more poorly on subsequent tasks that also demand self-control [15]. This temporary deficit in the skills needed to effectively manage thoughts, feelings and actions is known as a state of ego depletion [15]. Procedures or tasks that occupy attention are presumed to create cognitive load [16] (or reduce 'cognitive bandwidth' [17]). With reduced cognitive bandwidth, fewer processing resources are available for other information. Research suggests that both ego depletion and increased cognitive load undermine performance on tasks that require conscious, controlled and complex cognitive processes [18-20], such as resisting temptations in the food environment.

Arguably amongst the most important sources of cognitive load is financial strain: a constant stressor that forces daily difficult financial decision making on basic matters such as food and clothing. Previous studies have shown that relentless stress and a feeling of lack of control negatively impact health $[21,22]$. These results are in line with the 'scarcity theory' $[17,23]$, which suggests that dealing with scarcity (such as scarcity of money) takes up cognitive bandwidth that could otherwise be used to resist temptations [17].

In contemporary food environments, food is available anytime and anywhere, and the consumption of high-energy and ultra-processed foods is strongly promoted [24]. In such 'obesogenic' environments, food choices that are made while experiencing great financial strain or low perceived self-control are expected to be less healthy since the easy choice is often an unhealthy choice. However, research testing this hypothesis is still in its infancy. One study conducted among Canadian adults demonstrated that a relationship between a high level of mastery (a construct closely related to self-control) and lower metabolic risk (an outcome closely related to dietary intake) was most apparent in environments with higher fast-food exposure [25]. A cross-European study among adolescents showed that, although easy access to unhealthy food products was associated with higher consumption, the effect was attenuated when self-regulation strategies were used [26].

Building on the evidence that both low self-control and high financial strain are linked to unhealthier lifestyle behaviours and increased body weight [27-32], we aimed to examine whether associations between the local food environment and weight status differed across levels of self-control and financial strain. We hypothesized that unhealthier food environments are associated with higher body weight in those experiencing low self-control or great financial strain, but not or only weakly in individuals experiencing high self-control or no financial strain.

\section{Materials and Methods}

\subsection{Data}

We used cross-sectional data from the longitudinal Dutch population-based GLOBE study. Participants were adults (25-75 years) living in Eindhoven and surrounding cities. The $N=2812$ participants (45.5\% response rate) were representative of the source population (residents of Eindhoven and surroundings aged 25-75 years) in terms of health-related behaviours [33]. We used data from 2014, when participants were asked to complete a questionnaire. More detailed information on the objectives, study design and data collection of the Dutch GLOBE study can be found elsewhere [33]. The use of personal data in the GLOBE study follows the Dutch Personal Data Protection Act and the Municipal Database Act and has been registered with the Dutch Data Protection Authority (number 1248943). 


\subsection{Measures}

\subsubsection{Outcome Variables}

BMI was calculated using self-reported height and weight. Weight status was classified into normal weight $\left(18 \mathrm{~kg} / \mathrm{m}^{2}>\mathrm{BMI}<25 \mathrm{~kg} / \mathrm{m}^{2}\right)$, overweight $\left(25 \mathrm{~kg} / \mathrm{m}^{2} \geq \mathrm{BMI}<30 \mathrm{~kg} / \mathrm{m}^{2}\right)$ and obesity (BMI $\geq 30 \mathrm{~kg} / \mathrm{m}^{2}$ ).

\subsubsection{Exposure Variables}

Unhealthier food environments were defined as local neighbourhoods with (1) more opportunities to buy fast foods or takeaway meals, and (2) a higher totality of food retailers. Participants' home addresses were mapped using a geographic information system (GIS-ArcGIS 10, ESRI, Redlands, CA, USA). The location of food retailers dating from 2013 was also mapped in this GIS. Food retailer data was obtained from Locatus [34], a commercial company that performs yearly audits on all retailers in the Netherlands. We considered all fast food and take away outlets available in the Locatus database as fast food restaurants. In accordance with the classification of Lake et al. [35], fast food and take away outlets were defined as outlets serving hot food ordered and paid for at the till, foods cooked in bulk in advance and providing no or minimal table service (chain and non-chain fast food restaurants, take away and delivery outlets, grillrooms and kebab shops). The totality of food outlets consisted of the sum of all types of food outlets (e.g., supermarkets, greengrocers, convenience stores, bars, restaurants, etc.).

We calculated the density (number per $\mathrm{km}^{2}$ ) of fast food outlets and the totality of food outlets in Euclidean buffers of $400 \mathrm{~m}$ (representing a walk of approximately 5 minutes) and conducted sensitivity analyses with $250 \mathrm{~m}$ and $800 \mathrm{~m}$ buffer sizes (also walkable and cyclable distances).

Our exposure variables were non-normally distributed, but transformations did not improve the distribution. We therefore treated the untransformed densities as continuous variables to facilitate the interpretation of the main effects and effect modification (i.e., a 1-unit increase in the densities represents an increase of 1 food outlet per $\mathrm{km}^{2}$ in the $400 \mathrm{~m}$ buffer), and additionally conducted sensitivity analyses with density categorized into quartiles.

\subsubsection{Effect Modifiers}

Financial strain was assessed by two questions addressing (1) whether participants could make ends meet considering their monthly household income and (2) whether they had experienced any financial difficulties in paying bills for food, rent, electricity and so forth during the preceding year. Those two items were combined into having no, some or great financial strain: 'no financial strain' if they could make ends meet fairly easy or easy, or if they experienced no financial difficulties in the preceding year; 'some financial strain' if they could make ends meet with some difficulty or if they experienced some financial difficulties in the preceding year; and 'great financial strain' if they had great difficulty making ends meet or if they experienced great financial difficulties in the preceding year.

Self-control was measured using the Brief Self-Control Scale [36], a widely used instrument for measuring general trait self-control. Participants rated each of the 13 items (e.g., "I am good at resisting temptation") on a 5-point scale ranging from 1 (not at all like me) to 5 (very much like me). This scale was internally consistent (Cronbach's alpha $=0.78$ ) and could range from 13 to 65 . Self-control was divided into tertiles for stratified analyses.

\subsubsection{Confounding Variables}

Age (continuous in years), sex (male, female), country of birth (Netherlands, other), employment status (full-time employed, part-time employed, unemployed, retired, homemaker, other), length of residency (continuous in years), household equivalent income and educational level were selected a priori as potential confounders. Household equivalent income was measured as the level of household income per month divided by the square root of the number of people living from this income 
and divided into 5 categories: $1-<€ 1000 /$ month, $2-€ 1000-€ 1500 /$ month, $3-€ 1500-€ 2000 /$ month, $4-€ 2000-2500 /$ month and 5-> $€ 2500 /$ month. Highest attained educational level was classified according to the International Standard Classification of Education (ISCED): 1—primary education (ISCED 0-1), 2-lower secondary education (ISCED 2), 3-upper secondary education (ISCED 3-4), 4-tertiary education (ISCED 5-7).

\subsection{Analyses}

Assuming that missing data were missing at random, they were handled using multiple imputation for inferential statistics. The pattern of missingness showed that $40(<1 \%)$ participants had missing data on BMI and $414(15 \%)$ participants had missing data on any covariate or outcome measure. The chained equations function (with predictive mean matching for continuous variables, logistic regression for dichotomous variables, multinomial logistic regression for categorical variables and ordered logistic regression for ordered variables) was used to perform multiple imputation analyses. Based on the overall percentage missing values (13\%) we generated 13 multiple imputed datasets, as recommended by Rubin [37] and Bodner [38]. All variables described above were used in the imputation model and smoking, alcohol consumption, general health and wellbeing were treated as auxiliary variables.

Pooled results from the 13 imputed datasets were used in the regression models and non-imputed data were used to perform the descriptive analysis on the characteristics of the study population and their food environment.

Linear and multinomial logistic regression analyses were performed with body mass index and weight status as outcome variables, adjusted for confounders. Unadjusted and partially adjusted models were also explored, but given the similar results, only fully adjusted models are presented. Individuals with underweight (BMI $<18 \mathrm{~kg} / \mathrm{m}^{2} ; N=30$ ) were excluded from the analyses with weight status as outcome variable. Statistical significance was interpreted using $95 \%$ confidence intervals. Effect modification was assessed by stratifying the analyses by level of financial strain and self-control. Sensitivity analyses were conducted with density of fast food and the totality of food retailers in $250 \mathrm{~m}$ and $800 \mathrm{~m}$ buffers, and with densities divided in quartiles. All analyses were weighted by respondent-level sample weights to account for the sampling strategy used within the GLOBE study. All analyses were carried out in STATA, version 14.1 (StataCorp, College Station, TX, USA).

\section{Results}

Descriptive statistics are presented in Table 1 . The mean age of the sample was 49 years, $45 \%$ were male and the average length of residency in the neighbourhood was 16 years. The average density of the totality of food outlets in a $400 \mathrm{~m}$ buffer was 17 outlets per $\mathrm{km}^{2}$, and the density of fast food outlets was 4.1 outlets per $\mathrm{km}^{2}$.

Table 2 shows that one extra fast food outlet per $\mathrm{km}^{2}$ in a $400 \mathrm{~m}$ buffer was associated with a $0.04(95 \% \mathrm{CI}=-0.07 ;-0.01)$ lower body mass index. Similarly, one extra food outlet per $\mathrm{km}^{2}$ was associated with a $0.01(95 \% \mathrm{CI}=-0.01 ; 0.00)$ lower body mass index. The density of fast food outlets or the totality of food outlets were not significantly associated with weight status, although the direction of the coefficients suggests a negative association as well. Sensitivity analyses using $250 \mathrm{~m}$ and $800 \mathrm{~m}$ buffers instead of $400 \mathrm{~m}$ buffers resulted in comparable effect sizes in the same direction (Table S1). Sensitivity analyses using quartiles of densities showed similar negative associations with body weight, with the strongest effect sizes in quartile 4 (highest density; Table S2).

Table 3 displays the associations between measures of the food environment and body mass index stratified by levels of financial strain and self-control. A higher density of fast food outlets or totality of food outlets was mainly associated with a lower body mass index in individuals experiencing great financial strain $(B=-0.17,95 \% C I=-0.33 ;-0.02)$ and low self-control $(B=-0.09,95 \% C I=-0.15$; $-0.02)$. 
Similar patterns were found with weight status as the outcome (Table 4), although only the associations between food environment measures and overweight status in those experiencing great financial strain reached statistical significance. For example, one extra fast food outlet per $\mathrm{km}^{2}$ in a $400 \mathrm{~m}$ buffer was associated with a 0.90 -times lower relative risk of overweight and obesity.

Table 1. Sample characteristics.

\begin{tabular}{|c|c|}
\hline Measures & Total Sample $(N=2812)$ \\
\hline Age (mean (sd) years) & $48.8(14.9)$ \\
\hline Gender (N (\%) male) & $1332(44.8 \%)$ \\
\hline \multicolumn{2}{|l|}{ Household equivalent income } \\
\hline$\leq 1000 €$ per month & $351(14.3 \%)$ \\
\hline $1000-1500 €$ per month & $508(20.7 \%)$ \\
\hline $1500-2000 €$ per month & $608(24.8 \%)$ \\
\hline $2000-2500 €$ per month & $690(28.1 \%)$ \\
\hline$>2500 €$ per month & $298(12.1 \%)$ \\
\hline \multicolumn{2}{|l|}{ Educational level } \\
\hline Low (ISCED 0-2; $N(\%))$ & $761(25.8 \%)$ \\
\hline Medium (ISCED 3-4; $N(\%)$ ) & $740(25.1 \%)$ \\
\hline High (ISCED 5-8; $N(\%)$ ) & $1448(49.1 \%)$ \\
\hline Country of birth (N (\% Netherlands)) & $2480(88.5 \%)$ \\
\hline \multicolumn{2}{|l|}{ Employment status } \\
\hline Employed $(N(\%))$ & $1860(63.6 \%)$ \\
\hline Unemployed (N (\%)) & $234(20.4 \%)$ \\
\hline Retired $(N(\%)$ & $598(8.0 \%)$ \\
\hline Non-employed (N (\%)) & $232(7.9 \%)$ \\
\hline \multicolumn{2}{|l|}{ Children living in the household } \\
\hline No $(N(\%))$ & $1714(61.8 \%)$ \\
\hline Yes $(N(\%))$ & $1061(38.2 \%$ \\
\hline $\begin{array}{l}\text { Length of residency in the current neighbourhood } \\
\text { (mean (sd) years) }\end{array}$ & $16.3(13.4)$ \\
\hline Body mass index (mean $(\mathrm{sd}) \mathrm{kg} / \mathrm{m}^{2}$ ) & $25.6(4.9)$ \\
\hline Overweight $\left(\% \geq 25 \mathrm{~kg} / \mathrm{m}^{2}\right)$ & $34.4 \%$ \\
\hline Obesity $\left(\% \geq 30 \mathrm{~kg} / \mathrm{m}^{2}\right)$ & $18.1 \%$ \\
\hline Self-control (mean (sd) score) & $44.1(6.8)$ \\
\hline \multicolumn{2}{|l|}{ Financial strain } \\
\hline No financial strain $(N(\%))$ & $1864(68.1 \%)$ \\
\hline Some financial strain $(N(\%))$ & $689(25.0 \%)$ \\
\hline Great financial strain (N (\%)) & $208(6.9 \%)$ \\
\hline $\begin{array}{l}\text { Density of fast food outlets in a } 400 \mathrm{~m} \text { buffer } \\
\text { (mean (sd) count per } \mathrm{km}^{2} \text { ) }\end{array}$ & $4.1(4.8)$ \\
\hline $\begin{array}{l}\text { Density of all food outlets in a } 400 \mathrm{~m} \text { buffer } \\
\text { (mean (sd) count per } \mathrm{km}^{2} \text { ) }\end{array}$ & $17.0(27.1)$ \\
\hline
\end{tabular}


Table 2. Associations between measures of the food environment and body weight.

\begin{tabular}{lcccc}
\hline \multirow{2}{*}{ Exposure Variables } & \multirow{2}{*}{ Body Mass Index } & \multicolumn{3}{c}{ Weight Status } \\
\cline { 2 - 5 } & & Normal Weight & Overweight & Obesity \\
\cline { 2 - 4 } & $\mathbf{B ~ ( 9 5 \% ~ C I ) ~}$ & RRR (95\% CI) & RRR (95\% CI) & RRR (95\% CI) \\
\hline $\begin{array}{l}\text { Density of fast food outlets in a } \\
\text { l00 } \mathrm{m} \text { buffer }\end{array}$ & $\mathbf{- 0 . 0 4}(-0.07 ;-0.01)$ & Ref. & $0.99(0.97 ; 1.01)$ & $0.97(0.94 ; 1.00)$ \\
$\begin{array}{l}\text { Density of all food outlets in a } \\
400 \mathrm{~m} \text { buffer }\end{array}$ & $-\mathbf{0 . 0 1}(-0.01 ;-0.00)$ & Ref. & $1.00(0.99 ; 1.00)$ & $1.00(0.99 ; 1.00)$ \\
\hline
\end{tabular}

Note: $\mathrm{B}=$ regression coefficient. $\mathrm{RRR}=$ relative risk ratio. $\mathrm{CI}=$ confidence interval. Ref. = reference category. All analyses are adjusted for age, gender, education, children in the household, household equivalent income, employment status, country of birth and length of residency. 'Normal weight' was the reference category in the multinomial logistic regression analysis with weight status as dependent variable. Bold values represent statistically significant associations as defined by the $95 \%$ confidence interval.

Table 3. Associations between measures of the food environment in a 400m buffer and body mass index stratified by financial strain and self-control.

\begin{tabular}{|c|c|c|c|}
\hline \multirow{3}{*}{ Exposure Variables } & \multicolumn{3}{|c|}{ Body Mass Index } \\
\hline & High Self-control $(N=725)$ & Medium Self-control $(N=1059)$ & Low Self-control $(N=1012)$ \\
\hline & B $(95 \%$ CI $)$ & B $(95 \%$ CI $)$ & B $(95 \% \mathrm{CI})$ \\
\hline Density of fast food outlets & $-0.01(-0.07 ; 0.05)$ & $-0.03(-0.08 ; 0.03)$ & $-0.09(-0.15 ;-0.02)$ \\
\hline \multirow[t]{3}{*}{ Density of all food outlets } & $-0.00(-0.01 ; 0.01)$ & $-0.01(-0.01 ; 0.00)$ & $-0.01(-0.02 ;-0.00)$ \\
\hline & No Financial Strain $(N=1864)$ & Some Financial Strain $(N=689)$ & Great Financial Strain $(N=208)$ \\
\hline & B $(95 \%$ CI $)$ & B $(95 \%$ CI $)$ & B $(95 \% \mathrm{CI})$ \\
\hline Density of fast food outlets & $-0.04(-0.08 ; 0.00)$ & $-0.02(-0.10 ; 0.06)$ & $-\mathbf{0 . 1 7}(-0.33 ;-0.02)$ \\
\hline Density of all food outlets & $-\mathbf{0 . 0 1}(-0.01 ;-0.00)$ & $-0.00(-0.01 ; 0.01)$ & $-\mathbf{0 . 0 3}(-0.05 ;-0.00)$ \\
\hline
\end{tabular}

\section{Discussion}

We hypothesized that individuals with reduced cognitive bandwidth, operationalized as low perceived self-control and greater financial stress, are more vulnerable to unhealthy temptations in the food environment. We observed that associations between the food environment and body weight were stronger in those experiencing low self-control or great financial strain, but the direction of these associations was unexpected; that is, the density of fast food outlets and the totality of food outlets in the local neighbourhood were negatively related to body mass index and odds of being overweight and obese, and particularly among those with low levels of self-control and greater financial strain.

In the main analysis, every additional fast food outlet per squared kilometre was associated with a 0.04-point lower BMI. For a person of $1.80 \mathrm{~m}$ and $80 \mathrm{~kg}$, this translates to $0.13 \mathrm{~kg}$ less body weight. Associations with overweight and obesity were in the same direction and with similar small effect sizes but did not reach statistical significance. It is puzzling that, regardless the size of the local area considered, a higher availability of fast food outlets was associated with lower body weight. Similar but smaller associations were observed when analysing the totality of food outlets. This may suggest that the totality of food outlets reflects opportunities for buying healthier and unhealthier foods, more so than representing an overabundance of food outlets. 
Table 4. Associations between measures of the food environment in a $400 \mathrm{~m}$ buffer and weight status stratified by financial strain and self-control.

\begin{tabular}{|c|c|c|c|c|c|c|c|}
\hline \multirow{3}{*}{ Exposure Variables } & \multicolumn{7}{|c|}{ Weight Status } \\
\hline & \multirow{2}{*}{ Normal Weight } & \multicolumn{3}{|c|}{ Overweight } & \multicolumn{3}{|c|}{ Obesity } \\
\hline & & $\begin{array}{l}\text { No Financial } \\
\text { Strain }\end{array}$ & $\begin{array}{l}\text { Some Financial } \\
\text { Strain }\end{array}$ & $\begin{array}{l}\text { Great Financial } \\
\text { Strain }\end{array}$ & $\begin{array}{l}\text { No Financial } \\
\text { Strain }\end{array}$ & $\begin{array}{l}\text { Some Financial } \\
\text { Strain }\end{array}$ & $\begin{array}{l}\text { Great Financial } \\
\text { Strain }\end{array}$ \\
\hline & & RRR $(95 \%$ CI $)$ & RRR $(95 \% \mathrm{CI})$ & RRR $(95 \%$ CI) & RRR $(95 \%$ CI) & RRR $(95 \% \mathrm{CI})$ & RRR $(95 \% \mathrm{CI})$ \\
\hline Density of fast food outlets & Ref. & $1.00(0.97 ; 1.02)$ & $1.00(0.96 ; 1.04)$ & $0.90(0.83 ; 0.96)$ & $0.98(0.94 ; 1.02)$ & $0.96(0.90 ; 1.02)$ & $0.90(0.81 ; 1.00)$ \\
\hline \multirow[t]{3}{*}{ Density of all food outlets } & Ref. & $1.00(0.99 ; 1.00)$ & $1.00(0.99 ; 1.00)$ & $0.98(0.96 ; 0.99)$ & $1.00(0.99 ; 1.01)$ & $0.99(0.98 ; 1.00)$ & $0.98(0.97 ; 1.00)$ \\
\hline & \multirow{2}{*}{ Normal Weight } & \multicolumn{3}{|c|}{ Overweight } & \multicolumn{3}{|c|}{ Obesity } \\
\hline & & High Self-Control & $\begin{array}{c}\text { Medium } \\
\text { Self-Control }\end{array}$ & Low Self-Control & High Self-Control & $\begin{array}{c}\text { Medium } \\
\text { Self-Control }\end{array}$ & Low Self-Control \\
\hline & & RRR $(95 \%$ CI) & RRR $(95 \%$ CI) & RRR (95\% CI) & $\operatorname{RRR}(95 \% \mathrm{CI})$ & RRR $(95 \%$ CI) & RRR $(95 \%$ CI) \\
\hline Density of fast food outlets & Ref. & $1.00(0.96 ; 1.04)$ & $0.99(0.95 ; 1.02)$ & $1.00(0.97 ; 1.03)$ & $1.01(0.94 ; 1.08)$ & $0.98(0.92 ; 1.04)$ & $0.94(0.90 ; 0.99)$ \\
\hline Density of all food outlets & Ref. & $1.00(0.99 ; 1.00)$ & $1.00(0.99 ; 1.00)$ & $1.00(0.99 ; 1.00)$ & $1.00(0.99 ; 1.01)$ & $1.00(0.99 ; 1.01)$ & $0.99(0.98 ; 1.00)$ \\
\hline
\end{tabular}

Note: $\overline{R R R}=$ relative risk ratio. $\mathrm{CI}$ = confidence interval. Ref. = reference category. All analyses are adjusted for age, gender, education, children in the household, household equivalent income, employment status, country of birth and length of residency. 'Normal weight' was the reference category in the multinomial logistic regression analysis with weight status as dependent variable. Bold values represent statistically significant associations as defined by the $95 \%$ confidence interval. 
Our study is not the first to find unexpected results between the fast food environment and indicators of body weight: systematic reviews describe conflicting results in the literature [39-42]. The expected mechanism of this association is through dietary behaviour. Even though we did not have such data available for the present study, unexpected results in previous literature and in the current study are not likely to be attributable to the lack of these data: fast food is typically nutrient-poor, calorie-dense and high in fat, sugar and salt, and consumption at fast food restaurants is associated with higher energy intake and greater obesity risk $[43,44]$. The inconsistencies could thus be attributable to misclassification in the exposure variables: the missing link between the availability of fast food outlets and use of these outlets. A recent European study demonstrated that while access to fast food outlets in the home neighbourhood was not directly linked to fast food consumption or obesity, access to fast food outlets was associated with perceived availability and use of fast food outlets, and this was in turn associated with greater reported fast food consumption and unhealthier weight status [45]. In addition, a recent study demonstrated that exposure to food outlets in the residential neighbourhood was not representative of the overall foodscape exposure [46], and another study showed that the work and commuting environment also contribute substantially to the exposure to food outlets [47]. As such, the density of food outlets in the residential neighbourhood may not reflect the total exposure to food outlets individuals encounter in their daily lives. Studies using global positioning systems (GPS) may provide insight into what fast food outlets individuals are exposed to, and which of these outlets they visit [48]. In addition, it could be speculated that a higher density of food outlets in the residential neighbourhood is just a reflection of greater 'land use mix' (i.e., an area with multiple types of destinations, including food retailers), which previously has been linked to walking and lower rates of obesity $[49,50]$. We hypothesized that the food environment would be associated with higher body weight via dietary behaviour (energy intake) but did not investigate associations with energy expenditure: it may be that having more food outlets within a walkable and cyclable distance is in fact associated with more physical activity.

A previous study in the same cohort showed that low self-control and high financial strain are linked to unhealthier lifestyle behaviours and increased body weight [32], and we found evidence for an interaction between these social cognitive factors and the food environment. It is uncertain whether the influence of the food environment on obesity is always stronger in those with low self-control and high financial strain (i.e., would similar moderating effects be present had we observed a positive food environment-body weight association?), or whether this moderation is limited to the negative food environment-body weight association as observed in the present study. Future studies, preferably with more precise data on what temptations in the food environment individuals are actually exposed to, should investigate whether experiencing low self-control and great financial strain take up cognitive bandwidth that could otherwise be used to resist unhealthy temptations in the food environment, as proposed by the scarcity theory $[17,23]$.

\section{Strengths and Limitations}

This is the first study to investigate the potential moderating role of reduced cognitive bandwidth on the association between the local food environment and body weight. Although the study design (using questionnaires) will have excluded participants with low literacy and low mastery of the Dutch language, our sample was representative of the source population (residents of Eindhoven and surroundings aged 25-75 years) in terms of health-related behaviours [33]. Another strength is the linkage of two objective measures of exposure to the food environment with weight status. However, the results of this study should be interpreted in the light of its limitations. First, we used self-reported height and weight, and reporting bias by those with short height or high weight may have resulted in an underestimation of BMI and a potential misclassification of weight status [51]. This may have attenuated the associations under study. Second, exposure misclassification may have arisen because our measures of the food environment may not accurately reflect where participants bought food and where they experienced temptation to buy unhealthy food. We accounted for exposure misclassification 
due to area definitions by using different ego-centred buffers, but the density of fast food outlets and the totality of food outlets in the residential neighbourhood may not have captured the obesogenic aspects of the food environment well enough. Third, residual confounding in food environment research has been shown to result in null or weak findings [52], and this may be applicable in this study as well. Fourth, our study was unable to capture the complex system of interacting factors of influence on obesity [2], despite our investigation of the interaction between two environmental-level and two individual-level factors. This limitation includes the cross-sectional design, which restricted our opportunities of disentangling selection, causation and time-lag effects of food environments on body weight, and the lack of data on the hypothesized mediating variable dietary intake.

\section{Conclusions}

We did find support for a moderating role of self-control and financial strain, but associations between the food environment and weight status were not in the expected direction. Temptations in the food environment may be better captured by other measures than the density of (fast) food outlets, but interactions between unhealthy food environments and cognitive resources such as self-control should be further explored.

Supplementary Materials: The following are available online at http:/ /www.mdpi.com/1660-4601/16/4/674/s1, Table S1: Associations between measures of the food environment and body weight using alternative buffer sizes, Table S2: Associations between measures of the food environment and body weight using quartiles of food outlet density.

Author Contributions: Conceptualization, J.D.M. and F.J.v.L.; methodology, J.D.M., M.A.B., J.M.N., J.O.G., J.L. and F.J.v.L.; formal analysis, J.D.M.; data curation, J.O.G. and F.J.v.L.; writing-original draft preparation, J.D.M. writing - review and editing, J.D.M., M.A.B., J.M.N., J.O.G., J.L. and F.J.v.L.; funding acquisition, F.J.v.L.

Funding: The GLOBE study was supported by a grant from the Netherlands Organization for Health Research and Development (grant number 200500005). J.D.M.'s work was funded by an NWO VENI grant on "Making the healthy choice easier-role of the local food environment" (grant number 451-17-032). M.A.B., J.M.N., J.O.G. and F.J.v.L. are supported by a grant from the European Union Horizon 2020 Programme under grant agreement $n$ 667661 (Promoting mental wellbeing in the ageing population-MINDMAP). The study does not necessarily reflect the Commission's views and in no way anticipates the Commission's future policy in this area.

Acknowledgments: We are grateful to Locatus for providing geographical data on retailers' locations in the Netherlands.

Conflicts of Interest: The authors declare no conflict of interest. The funders had no role in the design of the study; in the collection, analyses, or interpretation of data; in the writing of the manuscript, or in the decision to publish the results.

\section{References}

1. Hruby, A.; Hu, F.B. The Epidemiology of Obesity: A Big Picture. Pharmacoeconomics 2015, 33, 673-689. [CrossRef] [PubMed]

2. Rutter, H.; Savona, N.; Glonti, K.; Bibby, J.; Cummins, S.; Finegood, D.T.; Greaves, F.; Harper, L.; Hawe, P.; Moore, L.; et al. The need for a complex systems model of evidence for public health. Lancet 2017, 390, 2602-2604. [CrossRef]

3. Rutter, H. The complex systems challenge of obesity. Clin. Chem. 2018, 64, 44-46. [CrossRef] [PubMed]

4. Savona, N.; Thompson, C.; Smith, D.; Cummins, S. Proportional responsibility versus individual responsibility for healthy eating: A complex systems analysis. Lancet 2017, 390, S80. [CrossRef]

5. Friel, S.; Pescud, M.; Malbon, E.; Lee, A.; Carter, R.; Greenfield, J.; Cobcroft, M.; Potter, J.; Rychetnik, L.; Meertens, B. Using systems science to understand the determinants of inequities in healthy eating. PLoS ONE 2017, 12, e0188872. [CrossRef] [PubMed]

6. Lakerveld, J.; Mackenbach, J.D. The upstream determinants of adult obesity. Obes. Facts 2017, 10, $216-222$. [CrossRef] [PubMed]

7. Hall, K.D. Did the Food Environment Cause the Obesity Epidemic? Obesity 2018, 26, 11-13. [CrossRef] [PubMed] 
8. Monteiro, C.A.; Moubarac, J.C.; Cannon, G.; Ng, S.W.; Popkin, B. Ultra-processed products are becoming dominant in the global food system. Obes. Rev. 2013, 14, 21-28. [CrossRef] [PubMed]

9. Baumeister, R.F.; Vohs, K.D. Self-Regulation, Ego Depletion, and Motivation. Soc. Personal. Psychol. Compass 2007, 1, 115-128. [CrossRef]

10. Vohs, K.D.; Heatherton, T.F. Self-regulatory failure: A resource- depletion approach. Psychol. Sci. 2000, 11, 249-254. [CrossRef] [PubMed]

11. Muraven, M.; Slessareva, E. Mechanisms of self-control failure: Motivation and limited resources. Personal. Soc. Psychol. Bull. 2003, 29, 894-906. [CrossRef] [PubMed]

12. Baumeister, R.F.; Vohs, K.D.; Tice, D.M. The strength model of self-control. Curr. Dir. Psychol. Sci. 2007, 16, 351-355. [CrossRef]

13. Hofmann, W.; Adriaanse, M.; Vohs, K.D.; Baumeister, R.F. Dieting and the self-control of eating in everyday environments: An experience sampling study. Br. J. Health Psychol. 2014, 19, 523-539. [CrossRef] [PubMed]

14. Carter, E.C.; Kofler, L.M.; Forster, D.E.; McCullough, M.E. A series of meta-analytic tests of the depletion effect: Self-control does not seem to rely on a limited resource. J. Exp. Psychol. Gen. 2015, 144, 796-815. [CrossRef] [PubMed]

15. Baumeister, R.F.; Bratslavsky, E.; Muraven, M.; Tice, D.M. Ego depletion: Is the active self a limited resource? J. Pers. Soc. Psychol. 1998, 74, 1252-1265. [CrossRef] [PubMed]

16. Engle, R.W. Working memory capacity as executive attention. Curr. Direct. Psychol. Sci. 2002, 11, 19-23. [CrossRef]

17. Mullainathan, S.; Shafir, E. Scarcity; Penguin Books Ltd.: London, UK, 2014.

18. Ariely, D. Controlling the information flow: Effects on consumers' decision making and preferences. J. Consum. Res. 2000, 27, 233-248. [CrossRef]

19. Drolet, A.; Luce, M.F. The rationalizing effects of cognitive load on emotion-based trade-off avoidance. J. Consum. Res. 2004, 31, 63-77. [CrossRef]

20. Schmeichel, B.J.; Vohs, K.D.; Baumeister, R.F. Intellectual performance and ego depletion: Role of the self in logical reasoning and other information processing. J. Pers. Soc. Psychol. 2003, 85, 33-46. [CrossRef] [PubMed]

21. Tucker-Seeley, R.D.; Li, Y.; Subramanian, S.V.; Sorensen, G. Financial hardship and mortality among older adults using the 1996-2004 Health and Retirement Study. Ann. Epidemiol. 2009, 19, 850-857. [CrossRef] [PubMed]

22. Kahn, J.R.; Pearlin, L.I. Financial strain over the life course and health among older adults. J. Health Soc. Behav. 2006, 47, 17-31. [CrossRef] [PubMed]

23. Mani, A.; Mullainathan, S.; Shafir, E.; Zhao, J. Poverty impedes cognitive function. Science 2013, 341, 976-980. [CrossRef] [PubMed]

24. Swinburn, B.; Egger, G.; Raza, F. Dissecting obesogenic environments: The development and application of a framework for identifying and prioritizing environmental interventions for obesity. Prev. Med. 1999, 29, 563-570. [CrossRef] [PubMed]

25. Paquet, C.; Dube, L.; Gauvin, L.; Kestens, Y.; Daniel, M. Sense of Mastery and Metabolic Risk: Moderating Role of the Local Fast-Food Environment. Psychosom. Med. 2010, 72, 324-331. [CrossRef] [PubMed]

26. De Vet, E.; de Wit, J.B.F.; Luszcynska, A.; Stok, F.M.; Gaspar, T.; Pratt, M.; Wardle, J.; De Ridder, D.T.D. Access to excess: How do adolescents deal with unhealthy foods in their environment? Eur. J. Public Health 2013, 23, 752-756. [CrossRef] [PubMed]

27. Shaw, B.A.; Agahi, N.; Krause, N. Are changes in financial strain associated with changes in alcohol use and smoking among older adults? J. Stud. Alcohol Drugs 2011, 72, 917-925. [CrossRef] [PubMed]

28. Siahpush, M.; Huang, T.T.; Sikora, A.; Tibbits, M.; Shaikh, R.A.; Singh, G.K. Prolonged financial stress predicts subsequent obesity: Results from a prospective study of an Australian national sample. Obesity 2014, 22, 616-621. [CrossRef] [PubMed]

29. Prentice, C.; McKillop, D.; French, D. How financial strain affects health: Evidence from the Dutch National Bank Household Survey. Soc. Sci. Med. 2017, 178, 127-135. [CrossRef] [PubMed]

30. De Ridder, D.T.D.; Lensvelt-Mulders, G.; Finkenauer, C. Taking stock of self-control: A meta-analysis of how trait self-control relates to a wide range of behaviors. Personal. Soc. Psychol. Rev. 2012, 16, 76-99. [CrossRef] [PubMed] 
31. Junger, M.; van Kampen, M. Cognitive ability and self-control in relation to dietary habits, physical activity and bodyweight in adolescents. Int. J. Behav. Nutr. Phys. Act. 2010, 7, 22. [CrossRef] [PubMed]

32. Beenackers, M.A.; Oude Groeniger, J.; van Lenthe, F.J.; Kamphuis, C.B.M. The role of financial strain and self-control in explaining health behaviours: The GLOBE study. Eur. J. Public Health 2018, 28, 597-603. [CrossRef] [PubMed]

33. Van Lenthe, F.J.; Kamphuis, C.B.M.; Beenackers, M.A.; Jansen, T.; Looman, C.W.N.; Nusselder, W.J.; Mackenbach, J.P. Cohort profile: Understanding socioeconomic inequalities in health and health behaviours: The GLOBE study. Int. J. Epidemiol. 2014, 43, 721-730. [CrossRef] [PubMed]

34. Locatus. Retail Facts 2012; Locatus: Woerden, The Netherlands, 2012.

35. Lake, A.A.; Burgoine, T.; Stamp, E.; Grieve, R. The foodscape: Classification and field validation of secondary data sources across urban/rural and socio-economic classifications in England. Int. J. Behav. Nutr. Phys. Act. 2012, 9, 37. [CrossRef] [PubMed]

36. Tangney, J.P.; Baumeister, R.F.; Boone, A.L. High self-control predicts good adjustment, less pathology, better grades, and interpersonal success. J. Pers. Soc. Psychol. 2004, 72, 271-324. [CrossRef]

37. Rubin, D.B. Multiple Imputation for Non-Response in Surveys; Wiley J \& Sons: New York, NY, USA, 1987.

38. Bodner, T.E. What improves with increased missing data imputations? Struct. Equ. Model. 2008, 15, 651-675. [CrossRef]

39. Fraser, L.K.; Edwards, K.L.; Cade, J.; Clarke, G.P. The geography of Fast Food outlets: A review. Int. J. Environ. Res. Public Health 2010, 7, 2290-2308. [CrossRef] [PubMed]

40. Fleischhacker, S.E.; Evenson, K.R.; Rodriguez, D.A.; Ammerman, A.S. A systematic review of fast food access studies. Obes. Rev. 2011, 12, e460-e471. [CrossRef] [PubMed]

41. Cobb, L.K.; Appel, L.J.; Franco, M.; Jones-Smith, J.C.; Nur, A.; Anderson, A.M. The relationship of the local food environment with obesity: A systematic review of methods, study quality, and results. Obesity 2015, 23, 1331-1344. [CrossRef] [PubMed]

42. Chennakesavalu, M.; Gangemi, A. Exploring the relationship between the fast food environment and obesity rates in the US vs. abroad: A systematic review. J. Obes. Weight Loss Ther. 2018, 8, 366.

43. Rosenheck, R. Fast food consumption and increased caloric intake: A systematic review of a trajectory towards weight gain and obesity risk. Obes. Rev. 2008, 9, 535-547. [CrossRef] [PubMed]

44. Nguyen, B.T.; Powell, L.M. The impact of restaurant consumption among US adults: Effects on energy and nutrient intakes. Public Health Nutr. 2014, 17, 2445-2452. [CrossRef] [PubMed]

45. Mackenbach, J.D.; Charreire, H.; Glonti, K.; Bárdos, H.; Rutter, H.; Compernolle, S.; De Bourdeaudhuij, I.; Nijpels, G.; Brug, J.; Oppert, J.-M.; et al. Exploring the relation of spatial access to fast food outlets with body weight: A mediation analysis. Environ. Behav. 2018. [CrossRef]

46. Wei, Q.; She, J.; Zhang, S.; Ma, J. Using individual GPS trajectories to explore foodscape exposure: A case study in Beijing Metropolitan Area. Int. J. Environ. Res. Public Health 2018, 15, 405.

47. Burgoine, T.; Forouhi, N.G.; Griffin, S.J.; Wareham, N.J.; Monsivais, P. Associations between exposure to takeaway food outlets, takeaway food consumption, and body weight in Cambridgeshire, UK: Population based, cross sectional study. Br. Med. J. 2014, 1464, 1-10.

48. Cetateanu, A.; Jones, A. How can GPS technology help usb etter understand exposure tot he food environment? A systematic review. SSM Popul. Heal. 2016, 2, 196-205. [CrossRef] [PubMed]

49. Christian, H.E.; Bull, F.C.; Middleton, N.J.; Knuiman, M.W.; Divitini, M.L.; Hooper, P.; Amarasinghe, A.; Giles-Corti, B. How important is the land use mix measure in understanding walking behaviour? Results from the RESIDE study. Int. J. Behav. Nutr. Phys. Act. 2011, 8, 55. [CrossRef] [PubMed]

50. Mackenbach, J.D.; Rutter, H.; Compernolle, S.; Glonti, K.; Oppert, J.M.; Charreire, H.; De Bourdeaudhuij, I.; Brug, J.; Nijpels, G.; Lakerveld, J. Obesogenic environments: A systematic review of the association between the physical environment and adult weight status. The SPOTLIGHT project. BMC Public Health 2014, 14, 233. [CrossRef] [PubMed] 
51. Maukonen, M.; Mannisto, S.; Tolonen, H. A comparison of measured versus self-reported anthropometrics for assessing obesity in adults: A literature review. Scand. J. Public Health 2018, 46, 565-579. [CrossRef] [PubMed]

52. Rummo, P.E.; Guilkey, D.K.; Ng, S.W.; Meyer, K.A.; Popkin, B.M.; Reis, J.P.; Shikany, J.M.; Gordon-Larsen, P. Does unmeasured confounding influence associations between the retail food environment and body mass index over time? The Coronary Artery Risk Development in Young Adults (CARDIA) study. Int. J. Epidemiol. 2017, 46, 1456-1464. [CrossRef] [PubMed] 